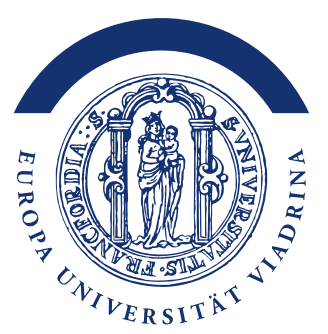

\title{
To vaccinate or not to vaccinate? This is the question! Delay the Booster, maybe you get a Bratwurscht!
}

Karl-Heinz Moritz

Georg Stadtmann

European University Viadrina Frankfurt (Oder)

Department of Business Administration and Economics

Discussion Paper No. 426

November 2021

ISSN 18600921 


\title{
To vaccinate or not to vaccinate? This is the question! Delay the Booster, maybe you get a Bratwurscht!
}

\author{
Karl-Heinz Moritz ${ }^{a}$ und Georg STADTMANN ${ }^{b}$
}

\section{Summary}

A game-theoretic setting is used to illuminate the conflict between vaccination proponents and vaccination opponents. A central result is that vaccination proponents could in principle persuade vaccination opponents to vaccinate by means of subsidization. Such a subsidy could increase benefits for both groups. Deeper analysis provides numerous further insights regarding the stability of these results.

Key words: vaccination, corona, covid, game theory, moral hazard

${ }^{a}$ FH Erfurt, moritz@fh-erfurt.de

${ }^{b}$ Korrespondierender Autor: Europa-Universität Viadrina, Große Scharrnstr. 59, 15230 Frankfurt (Oder), stadtmann@europa-uni.de 


\section{Contents}

1 Introduction 3

2 A game theoretical approach $\quad 4$

2.1 Assumptions of the game . . . . . . . . . . . . . . 4

2.2 Solution to the game . . . . . . . . . . . . . 6

2.3 Interpretation . . . . . . . . . . . . . . . 7

$\begin{array}{llr}3 & \text { Conclusion } & 9\end{array}$

\section{List of Tables}

1 Cost and benefit from the vaccination . . . . . . . . . 4

2 Pay-off matrix . . . . . . . . . . . . . . . . . 5 


\section{Introduction}

The relationship between the vaccinated group and the unvaccinated group is currently very conflictual. The vaccinated group accuses the unvaccinated group that their behaviour is contributing to fuelling the pandemic. The unvaccinated, on the other hand, often invoke the right to physical integrity. This paper analyses the different lines of argumentation from a gametheoretical perspective. In the end, even we will not be able to bring about a solution to the conflict. Nevertheless, we believe we can point out options for action and describe their long-term consequences relatively clearly.

The situation between the vaccination supporters and the vaccination opponents is somewhat similar to the traditional example of the conflict between the non-smoker and the smoker in a train compartment. The smoker would like to smoke but creates a negative externality for the non-smoker. The nonsmoker claims the air as his personal good, which should not be polluted. According to Coase, this conflict can be resolved through negotiation:

- One solution could be that the non-smoker pays the smoker money to stop smoking.

- The other solution is for the smoker to compensate the non-smoker for being allowed to pollute the air.

Whether one or the other solution comes about depends in particular on who owns the property rights to the air. Whereas in the past it was allowed to smoke on trains, today it has become accepted that the property right belongs to the non-smoker. Furthermore, it should be noted that a successful negotiation is more likely, the lower the number of involved parties.

With regard to the vaccination issue, it also seems to have been regulated initially that unvaccinated people were allowed to hurl viruses in public spaces. 
However, the current restrictions (2G in restaurants) tend to give ownership to the vaccinated.

\section{A game theoretical approach}

\subsection{Assumptions of the game}

In the following, the situation between the two parties is presented using a payout matrix. This is based on the following assumptions, which are described in Table 1. The payoff matrix is shown in Table 2.

Table 1: Cost and benefit from the vaccination

\begin{tabular}{|l|c|c|}
\hline Achieved utility without vaccination & Supporters & Opponents \\
\hline $\begin{array}{l}\text { Direct effect: Increase in utility } \\
\text { through vaccination }\end{array}$ & +9 & 0 \\
\hline $\begin{array}{l}\text { Costs of vaccination (queue, swellings, } \\
\text { potential short or long run damages } \\
\text { from the vaccination) }\end{array}$ & -1 & -3 \\
\hline $\begin{array}{l}\text { (Positive) external effect in case that } \\
\text { other group gets vaccinated }\end{array}$ & +7 & 0 \\
\hline
\end{tabular}

This table contains important assumptions! Some vaccination opponents argue that vaccination could produce long-term vaccine damage. If this is the case, vaccination supporters would incur high costs for the health system in the future. This negative externality would also have to be borne by vaccination opponents. Furthermore, some vaccination opponents do not want to be in the same room with vaccinated people because they are afraid that something could jump over. We explicitly exclude these arguments, although they are relevant from the point of view of some vaccination opponents and determine their behaviour. 
Table 2: Pay-off matrix

\begin{tabular}{|c|c|c|c|}
\hline \multicolumn{2}{|c|}{} & \multicolumn{2}{|c|}{ Opponents } \\
\cline { 3 - 4 } \multicolumn{2}{|c|}{} & vaccinate & don't vaccinate \\
\hline \multirow{3}{*}{ Supporters } & vaccinate & $11 /-3$ & $4 / 0$ \\
\cline { 2 - 4 } & don't vaccinate & $3 /-3$ & $-4 / 0$ \\
\hline
\end{tabular}

- If the group of vaccine supporters does not get vaccinated and the opponents also remain unvaccinated, the supporters achieve a payoff of -4 and the opponents achieve a payoff of 0 (bottom right panel).

- If - starting from the lower right field - only the vaccination supporters get vaccinated, their benefit changes as follows:

Baseline $(-4)+$ direct effect of vaccination $(+9)-$ cost of vaccination $(-1)+$ no positive external effect, because the opponents do not get vaccinated $\Rightarrow$ benefit level achieved $=4$.

The vaccination opponents remain unvaccinated. We assume that the vaccination opponents do not care whether the vaccination supporters have been vaccinated or not. Their benefit remains at 0 (upper right field).

- If - starting from the bottom right panel - the opponents get vaccinated, their utility drops to -3 . The supporters remain unvaccinated, but feel a positive externality of the order of +7 :

Baseline $(-4)+$ positive external effect, because the opponents get vaccinated $\Rightarrow$ benefit level achieved $=+3$.

- If both the vaccination supporters and the vaccination opponents are vaccinated, the vaccination supporters achieve the following benefit level:

Baseline $(-4)+$ direct effect of vaccination $(+9)+$ costs of vaccination $(-1)+$ positive external effect because the opponents also get vaccinated $(+7) \Rightarrow$ benefit level achieved $=11$. The payoffs are thus 11 for the vaccination supporters and -3 for the vaccination opponents (top left panel). 


\subsection{Solution to the game}

To solve the game, the concept of dominant strategy is applied:

- If the opponents play "don't vaccinate", the supporters must compare the payoffs of -4 (don't vaccinate) and +4 (vaccinate). Thus, the best answer of the vaccination supporters is "vaccinate".

- If the opponents of vaccination play "vaccinate", the best answer of vaccination supporters is "vaccinate".

Thus, the "vaccinate" option is a dominant strategy for vaccination supporters.

- If the vaccination supporter play "don't vaccinate", the best answer of the opponents is "don't vaccinate".

- If the vaccination supporters play "vaccinate", the best answer of the opponents is "don't vaccinate".

Therefore, the option "do not vaccinate" is a dominant strategy for the opponents of vaccination.

Thus, the equilibrium of the game is a situation in which the vaccination supporters vaccinate and the vaccination opponents do not vaccinate. This equilibrium can also be characterised as a Nash equilibrium.

Since this is an equilibrium in dominant strategies, the result does not change even if the decision situation is modelled as an infinitely repeated game or a sequential game. 


\subsection{Interpretation}

At first glance, this result may not come as a surprise. However, the precise analysis and the interpretation provide important insights:

1. The balance is pareto optimal. No group can improve (at first) without the other group getting worse.

2. Thus, the equilibrium is not a prisoner's dilemma.

3. In the equilibrium, the sum of all payoffs - i.e. the payoff for society - is not maximal. According to the Kaldor-Hicks criterion, vaccinate/vaccinate with a total payoff of $8(11-3)$ would therefore be preferable to the situation vaccinate/non-vaccinate with a total payoff of $4(4+0)$.

Let's put ourselves in the shoes of the vaccination supporters. There are two ways to convince the anti-vaccinationists to vaccinate:

- The vaccination supporters could subsidise the vaccination opponents.

- The group of vaccination opponents could be sanctioned by the government.

Let us first consider subsidisation: The pro-vaccination group could convince the anti-vaccination group to get vaccinated by paying, say, slightly more than 3 monetary units. This payment would put both the vaccination supporters and the vaccination opponents in a better position than in the equilibrium solution outlined above. Thus, an improved situation - compared to the existing equilibrium - is possible through a negotiated solution and a payment.

However, this solution has some side effects: 
1. If people find that a refusal attitude is later compensated, a refusal attitude could even be bred. Potential vaccination supporters would only be boosted if vaccination is rewarded with a subsidy (moral hazard problem).

2. Vaccination supporters might find the payment of compensation unacceptable on ethical-emotional grounds. The payment itself would violate their sense of justice and thus reduce their benefit. The question is whether, taking this aspect into account, there is still sufficient room for distribution.

3. The groups are of course not homogeneous. While for some vaccination opponents an incentive in the form of a bratwurst is sufficient, for other vaccination opponents much higher payments would have to be promised. The internal costs of the vaccination opponents could become prohibitively high, for example, if they - for example - amount to 20 monetary units. In this respect, however, it must also be taken into account that not even the last vaccination opponent necessarily has to be convinced. For the extreme case, this means: The "last opponent of vaccination" does not have to be convinced at all and has no "blackmail potential".

Alternatively, sanctions could convince the vaccination opponents to vaccinate: For example, IW president Hüther (2021) has suggested making the vaccination opponents pay for a stay in the intensive care unit themselves. Justus Haucap has also taken up this suggestion and brought into play a co-payment of $20 \%$ of hospital costs by the unvaccinated (cf. Gersemann 2021).

In principle, of course, a state vaccination obligation with an administrative fine of e.g. 20 EUR per day would be conceivable. The former Minister of State for Culture Nida-Rümelin (2021) argues: "Similar to fare evasion, a stubborn refusal can grow from an administrative offence to a criminal offence." This measure would also increase costs for the unvaccinated. 
However, it seems problematic that this intervention would be seen by the anti-vaccination group as involuntary and not liberal, and possibly also as undemocratic or dictatorial. A turn towards extremist parties and different behaviour would be expected. Therefore, the negotiated solution has a greater charm.

\section{Conclusion}

A game-theoretical analysis has shown that the combination of provaccinationists and anti-vaccinationists is a Nash equilibrium but not a prisoner's dilemma. The equilibrium in the base game is pareto-optimal. A negotiated solution is conceivable in principle. However, due to the size of the group and the heterogeneity in the group of vaccination opponents, such a solution is unlikely. 


\section{Literature}

Gersemann, Olaf (2021): Vorbild Singapur? Ökonomen bringen für Deutschland drastische Maßnahmen ins Spiel. Die Welt online 13.11.2021. https://www.focus.de/gesundheit/coronavirus/ kostenbeteiligung-an-krankenhaus-rechnung-vorbild-singap ur-ungeimpfte-muessen-klinik-aufenthalt-wegen-corona-tei ls-selbst-zahlen_id_24425613.html

Hüther, Michael (2021): Finanzielle Sanktionen für Impfunwillige - jetzt ist die Zeit dafür gekommen. Die Welt online 12.11.2021. https://www . welt.de/wirtschaft/plus235019196/Finanzielle-Sanktionen-fu er-Impfunwillige-jetzt-ist-die-Zeit-dafuer-gekommen.html

Nida-Rümelin, Julian (2021): Ein Vorschlag zur Güte. Die Welt online 21.11.2021. https://www.welt.de/debatte/kommentare/plus23517 7702/Impfpflicht-Ein-Vorschlag-zur-Guete.html 